\title{
Production of Liquid and Solid Fuel by the Technique of Microwave Pyrolysis of Scrap Tires and its Analysis
}

\author{
Kaleemullah $^{1}$, Ben Haoxi ${ }^{2 *}$, Zhihong Wu ${ }^{3}$ \\ ${ }^{1,2,3}$ Key Laboratory of Energy Thermal Conversion and Control of Ministry of Education, School of Energy and \\ Environment, Southeast University, Nanjing, China Nanjing, China \\ kaleemullahkatpar45@gmail.com¹, benhaoxi@gmail.com²,18915408402@163.com³ \\ corresponding author*: benhaoxi@gmail.com \\ Received: 27 April, Revised: 21 May, Accepted: 12 June
}

\begin{abstract}
The discussion in this paper is about the possible use of microwave pyrolysis technique as an energy-capable alternative to present heating techniques in biomass waste processing and treatment for renewable energy system. The wreck tires have relevant disposal or recycling issues under environment and financial and sustainable modes. These techniques can be a challenging for manufacturing and intellectual learning researches. In this competition, pyrolysis is a latest, strong substitute to the reprocessing of useless tires, until unless it will be possible to produce value adding results. In any case, upgrades in warmth exchange innovation are fundamental to enhance the plenitude of the procedure. Here we are describing the usage of microwave radiation (MW) as one of the most beneficial heating skills for pyrolysis. Whereas, there are different techniques for the process of the waste tires in previous era, such as crushing to get crumbs and rubber powder, burning them in cement furnaces for thermal power generation, re-stepping, decomposition by chemicals Heat degradation of rubber materials. The important and valuable chemicals in commercial use are derived from oils which are obtained from pyrolysis process by subjecting the pyrolytic oils to a fraction distillation at a temperature of about $207^{\circ} \mathrm{C}$ (under atmospheric) pressure for the product of at least one commercially valuable Chemical to isolate at least one commercially valuable chemical. Some of the selected chemicals from the group, consisting of paraffin, naphenes, olefins and flavorings. Particularly valuable chemicals that can be extracted from ripe pyrolytic oils are benzene, toluene, xylene, styrene and lime dl. The distillation fraction, which boils above $204^{\circ} \mathrm{C}$, can be used as an extension oil in the production of various rubber and plastic parts. An improved process for producing the carbon black by microwave pyrolysis (MWP) of used rubber tires is also revealed. The recovered products which have high commercial value indicates advantage over traditional, more destructive disposal methods, and it also advice the very great capability for measuring the process and feedback to the commercial as well as industrial level.
\end{abstract}

Keywords - Pyrolysis, Microwave Heating, Pyrolytic Oil, Biomass, Renewable Energy, waste Tires. Rubber.

\section{INTRODUCTION}

Pyrolysis is a process that has an vital prospective within the biomass refinery so that it can convert Bearable, by heating the lignocellulosic biomass raw material between $400^{\circ}$ $\mathrm{C}$ to $600^{\circ} \mathrm{C}$ or more, supplying fuel and chemical substances in the absence of oxygen[1,2]. The natural lower thermal conductivity of biomass means that conduction is the ratedetermining step, and heating times can be of the order of several minutes[3].It is imperative that we use appropriate technologies for the upgrading of resources from unconventional sources such as waste to alleviate the energy crisis and slow environmental degradation, which, in turn, will be the percentage of buried Reduce waste[4]. The term "pyrolysis" can be explained as a thermal degradation while oxygen is not present which alters a raw material into various reactive intermediate products such as solid (char), liquid (heavy molecular weight) and gaseous products (light molecular weight gases) [5]. The power conversion of the waste tires with pyrolysis has been tested in step with the working conditions parametrically [6].

The understanding of the pyrolysis process is a complicated one since many factors have to be considered, such as raw material composition and experimental conditions. In terms of its physical form (structural arrangements, thermal conductivity and specific heat) and chemical characteristics (organic and inorganic composition), the proficiency of MP procedures depends enormously on the idea of the material being prepared. Therefore, not all materials present a similar dielectric conduct, and along these lines, not all materials are also heated by microwaves[7]. While the period of the MP, it is necessary to accentuate that not only the receptor will captivate microwave energy to yield heat; the solid excess formed in the process also donates to the concluding pyrolysis temperature. Microwave (MW) is a standout amongst the utmost encouraging heating skills for pyrolysis because of its capacity of warming rapidly and 
legitimately any MW engrossing material Polymers don't be able to assimilate MW and transform them into warmth.

The aim of this chapter is to emphasize the principles of MP and to show recent research on the application of this technology to waste treatment. As an introduction to the topic, a brief background on the pyrolysis process and the fundamentals of microwave irradiation as an energy source are presented.

\section{A. Essential features of pyrolysis}

- Very high heating and heat transfer rates, which require a finely ground feed.

- Deliberately controlled response temperature of around $600 \mathrm{C}$ in the vapor stage

- Stay time of pyrolysis vapors in the reactor less than $1 \mathrm{sec}$

- Extinguishing (fast cooling) of the pyrolysis vapors to give the bio-oil item

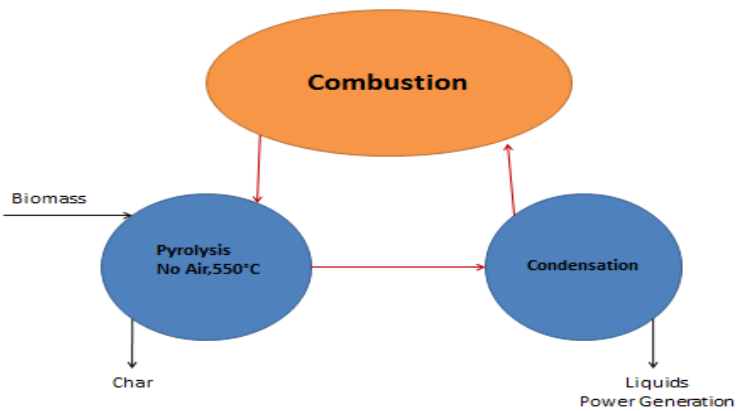

Figure 1. Biomass Liquefaction via Pyrolysis

\section{B. Sufficient level MW Pyrolysis}

The pyrolysis can be relatively small and untraceable, which lowers the cost of transporting and handling energy resources from biomass. Heat transfer has a critical area because the process is compromised and a sufficient level of heat transfer is provided to meet the heat demand of the process. Biomass pyrolysis offers an adaptable and alluring method for changing over natural issue into vitality items which can be effectively utilized for the generation of warmth, power and synthetic substances.

A wide scope of biomass feedstocks can be utilized in pyrolysis forms[8]. The pyrolysis procedure is subject to the dampness substance of the feedstock, which should to be about $10 \%$. At high dampness substance, large amounts of water are delivered and at lower levels there is a hazard that the procedure just creates dust rather than oil.. High-dampness squander streams, for example, slime and meat handling squanders, require drying before exposing to pyrolysis.

\section{Pyrolysis Process}

It is the thermal transformation of raw resources just like fuel and wastes in a closed system, without delivering extra external components in particular oxygen the presence of which modifies the alignment of the acquired product. The pyrolysis is one of the secondary fuel conversion procedures; since in this method we can notice the conversion of one fuel form into another generally the other form is not so difficult to work with. After the pyrolysis process is concerned to the solid energy, it is called "gasification", in the situation of liquid or gas fuels "cracking".

In exercise the methods of thermal conduct of waste frequently run by a small quantity of the air. Ultimately this leads to a fractional gasification. It can be presumed that pyrolysis arises in the interior sector of the bed. These methods are habitually called as "quasi-pyrolysis". Below are the three dissimilar substrates that can be positively used in a method of pyrolysis are shortly defined.

\section{Types of Pyrolysis}

Pyrolysis can also be based on the environment called oxidative pyrolysis, hydro-pyrolysis, vapor pyrolysis, catalytic pyrolysis and vacuum pyrolysis, as well as according to the heating system such as microwave or plasma pyrolysis. Other reactive types just like the AR and the rotary kon (mostly it is used for the construction of liquid, because of the large heating rate and the steam siding less period), can similarly be used for quick pyrolysis.

\section{E. Tire composition}

Tires are made of rubber (60-65 wt\%), carbon black (CB) (25-35 wt \%) and the rest consists of accelerators and fillers, which are added during the manufacturing process[10]. The rubbery materials are present in the form of $\mathrm{CxHy}$ with some fibrous materials and they are considered thermoset polymers. Vehicle tires (both passenger and truck) are mainly a blend of natural (NR) and synthetic rubber (SR) such as butyl rubber (BR) and styrene-butadiene copolymer (SBR). The NR comes from the Hevea tree, whilst the SR is generally derived from petroleum- based products. NR has unique elastic properties and it is an essential element of a tire[11]. Rubber comprises elastomeric polymers characterized by the presence of a network structure that can be temporarily deformed when subjected to external forces. According to the International Rubber Study Group 24.37 million tons of rubbers were produced in 2010. Of this amount, 10.38 million tons (42\%) were NR and the remaining 13.99 million tons (58\%) were SR. The materials of modern pneumatic tires are synthetic rubber, natural rubber, fabric and wire, along with carbon black and other chemical compounds. They consist of a tread and a body. The tread provides traction while the body provides containment for a quantity of compressed air. Before rubber was developed, the first versions of tires were simply bands of metal fitted around wooden wheels to prevent wear and tear. Early rubber tires were solid (not pneumatic). Pneumatic tires are used on many types of vehicles, including cars, bicycles, motorcycles, buses, trucks, heavy equipment, and aircraft.[11] Metal tires are still used on locomotives and railcars, and solid rubber (or other polymer) tires are still used in various non-automotive applications, such as some casters, carts, lawnmowers, and wheelbarrows.

\section{F. Pyrolysis technologies with respect to different Experimental materials}

\section{1) Materials}


The crude material is a blend of light obligation vehicles non-destroyed waste tires with piece sizes differing from 2 to $10 \mathrm{~cm}$. Prior to investigation, the tire pieces were cleaned and dried at room temperature in a well-ventilated zone.

\section{2) Analyses of Tires}

The fundamental examination has taken place on a $\mathrm{C}, \mathrm{H}$, N, S-O Analyzer (Flash EA 1112 Series), with detection perimeter of $0.05 \% \mathrm{wt}$, however for higher heating rate (HHV) measurements a PARR 6200 Calorimeter was used.

\section{3) Laboratory Scale Reactor Experiments}

The pyrolysis trials were performed at $500^{\circ} \mathrm{C}$ by fluctuating the warming rate inside the scope of $5-15^{\circ} \mathrm{C} / \mathrm{min}$. Before each test the reactor was inserted with nitrogen. Utilizing a gas-chromatograph with warm conductivity indicator (TCD/GC), the gas has been dissected at each 20min amid the warm scope of tires debasement. The analysis shows that the gases are mainly formed starting from $400^{\circ} \mathrm{C}$ and the major mixtures are $\mathrm{H} 2$ (25-29\% vol) and $\mathrm{CH} 4$ (22-25\%vol). The strong and condensable items yields are resolved and the gas yield is determined by distinction[13]

\section{G. Previous Studies and researches on tire pyrolysis}

Henne and Midgley considered the damaging refining of elastic in a progression of 18 papers amid the late 1920s and mid-1930s. They explored that isoprene and dependent were the commanding results of the elastic refining. From a mechanical perspective, a few creators called attention to that pyrolysis of WT was first endeavored by the US Bureau of Mines in a joint effort with the Firestone Company in the US in the mid-1970s. A 10 tire for each day lab unit was created with a generation of 3.91 of fluid. $3.1 \mathrm{~kg}$ of roast, $1.3 \mathrm{~kg}$ of gas and $1 \mathrm{~kg}$ of steel and scorch per tire pyrolysed.

From a modern perspective, a few creators called attention to that pyrolysis of scrap tires was first endeavored by the US Bureau of Mines as a team with the Firestone Company in the US in the mid-1970s. A 10 tire for each day research facility unit was created with a generation of 3.91 of fluid. $3.3 \mathrm{~kg}$ of char.

\section{EXPERIMENTS, PROCESS AND RESULTS}

The examples are squandering tire powders which are broadly accessible in China. Table I gives the estimated and ultimate investigation. The warming rate in the test are $10^{\circ} \mathrm{C} / \mathrm{min}, 20^{\circ} \mathrm{C} / \mathrm{min}$ and $40^{\circ} \mathrm{C} / \mathrm{min}$ individually. The starting temperature is room temperature and the last temperature is set to be $600^{\circ} \mathrm{C}$ or $800^{\circ} \mathrm{C}$. The tire is warmed within the sight of nitrogen gas.

Table I: Immediate and Decisive examination

\begin{tabular}{|l|l|l|l|l|}
\hline \multicolumn{2}{|l|}{ Immediate examination } & $\begin{array}{l}\text { Qb,ad } \\
(\mathrm{J} / \mathrm{g})\end{array}$ \\
\hline Mad\% & Aad\% & Vad\% & FCad\% & 39565 \\
\hline 0.81 & 7.42 & 64.69 & 27.17 & \\
\hline Decisive Examination & \multicolumn{2}{l|}{} \\
\hline Cad\% & Had\% & Nad\% & Sad\% & Oad\% \\
\hline 81.84 & 6.06 & 1.79 & 1.64 & 0.48 \\
\hline
\end{tabular}

\section{A. Illustration of pyrolysis}

The pyrolysis of discarded tire is explained as the next process:

$$
\mathrm{a}(\mathrm{s}) \rightarrow \mathrm{b}(\mathrm{s})+\mathrm{c}(\mathrm{g})
$$

However s is solid and is gas. The above equation is summarized by that the discarded tire, "a" converted into a solid which is represented as "b", and a gas which is represented as "c" during the pyrolysis. The gassy section, c, was separated by nitrogen gas while the analysis was going on, which avoid the changeable response took place and confirmed the matching of permanent response with the research.

The weight loss rate can be distinct as:

$$
\frac{\mathrm{da}}{\mathrm{dt}} \mathrm{Kf}(=\mathrm{kf}(\alpha)
$$

where $\alpha$ is the proportion of weight cost at time $t$ and is distinct as:

$$
\alpha=\mathrm{W} 0-\frac{W_{t}}{W_{0}}-\mathrm{W} \infty
$$

where W0 is the early load, Wt is the weight at time t and $\mathrm{W} \infty$ is the weight when the reaction stops. Where as the rate constant $\mathrm{k}$ has a closely proportional to the temperature $\mathrm{T}$ and according to the Arrhenius's law it can be formulated as:

$$
\mathrm{k}=\mathrm{A} \exp \left(-\frac{\mathrm{E}}{\mathrm{RT}}\right)
$$

whereas

$\mathrm{A}=$ factor of frequency

$\mathrm{E}=$ activation energy

$\mathrm{R} \mathrm{i}=$ gas constant

$\mathrm{T}=$ total temperature

The heating rate $\beta$ was set as unceasing in the experimentation, $\beta=\mathrm{dTdt}$.

Familiarizing $\beta$ and equation (4) into equation (1) yields:

$$
\frac{\mathrm{da}}{\mathrm{f}(\mathrm{\alpha})=}=\frac{\mathrm{A}}{\mathrm{B}} \cdot \exp \left(-\frac{\mathrm{E}}{\mathrm{RT}}\right) \mathrm{dT}
$$

Differential and integral are the two procedures to answer the equation.

The differential technique uses the DTG data right to define $\mathrm{f}(\alpha)$, where as the integral process links the integration of equation (5) and the TG data to resolve $f(\alpha)$.

Define $G(\alpha)=\int \alpha 0 \operatorname{d} \alpha f(\alpha)$ and yields:

$$
\mathrm{G}(\alpha)=\mathrm{A} \beta \int_{\mathrm{To}}^{\mathrm{I}} \exp \left(-\frac{\mathrm{E}}{\mathrm{RT}}\right) \mathrm{dT}
$$

While $\mathrm{T}_{0}=$ initial temperature of pyrolysis. Integrate equation (6) among $0 \sim \alpha$ and $0 \sim \mathrm{T}$ correspondingly described as:

$$
\int_{0}^{\alpha \mathrm{d} \alpha}=\mathrm{G}(\alpha)=\frac{\mathrm{A}}{\mathrm{f} \alpha} \int_{\mathrm{To}}^{\mathrm{T}} \exp \left(-\frac{\mathrm{E}}{\mathrm{RT}}\right) \mathrm{dT}
$$


Coats and Redfern [15] derived the integration of the right hand side of equation (7)

According to temperature calculation method [16] and we get: While $\ln \left[\frac{G(a)}{T^{2}}\right]$ is related to $\frac{\mathbb{1}}{\mathrm{T}}$ with the slope $-\frac{\mathrm{E}}{\mathrm{RT}}$ and intercept, $\ln \frac{A R}{\beta E}$

The relating connection coefficient was taken as a list for assurance of sensible component work. The gas-strong response instrument work with a most extreme connection coefficient was chosen as the component work for tire pyrolysis. The initiation vitality $\mathrm{E}$ and the recurrence factor $\mathrm{A}$ were then determined by the direct line work.

\section{B. Process}

The process of pyrolysis of excess tire experiences numerous phases at a given heating rate. Figure 2 and Figure 3 clearly describes the thermogravimetric and the resulting thermogravimetry shape parallel to the method of pyrolysis of the excess tire fine particles, illuminating its quantity loss fraction and mass loss rate vs. temperatures[14]. The heating rate is set to be $\beta=10,20$ and $40^{\circ} \mathrm{C} / \mathrm{min}$ and the tire precipitate size is 60,200 and 200 mesh. At the point when the temperature expanded from room temperature to under $200^{\circ} \mathrm{C}$, weight reduction was watched. The marginally variety of the mass misfortune at the beginning period of the TG profile was because of the arrival of the dampness in the tire From that point forward, the TG bend kept level until about $200^{\circ} \mathrm{C}$. At the point when the temperature surpassed about $200^{\circ} \mathrm{C}$, mass misfortune started, which was because of the warm deterioration of the blend of oil, plastifiers and different added substances, At the point when the temperature expanded from $200^{\circ} \mathrm{C}$ to about $400^{\circ} \mathrm{C}$, the nonstop contribution of vitality activated critical tire pyrolysis responses. Therefore, a greatest mass misfortune rate top was seen at $381.3^{\circ} \mathrm{C}$ on the DTG bend for 100 -work tire powder at warming rate of $10^{\circ} \mathrm{C} / \mathrm{min}$, as appeared by Fig 2. In the meantime, unpredictable parts started to dissipate which brought about a weight reduction of around $15 \%$ on the TG bend. At the point when temperature expanded from $400^{\circ} \mathrm{C}$ to $480^{\circ} \mathrm{C}$, concentrated vanishing of the volatiles occurred and created a high weight reduction with a most extreme rate at $453.5^{\circ} \mathrm{C}$ on the DTG bend.

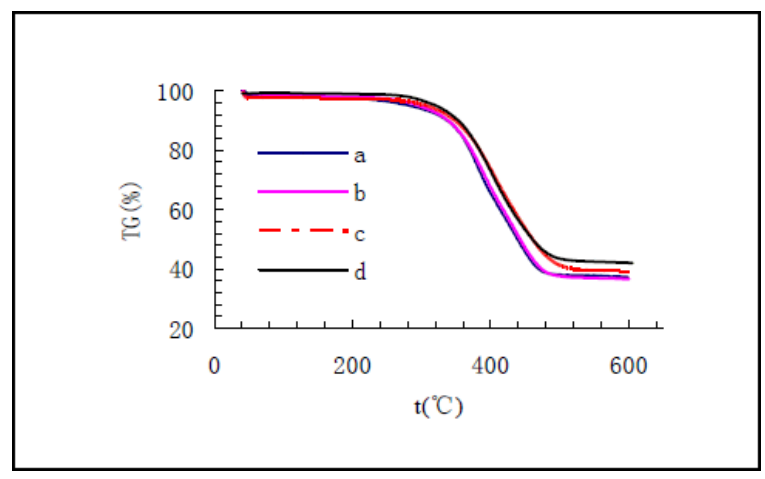

Figure 2. TG bend for 100 lattice tire dust at dissimilar heating amount (a: $10 \mathrm{c} / \mathrm{m}, \mathrm{b}: 20^{\circ} \mathrm{C} / \mathrm{m}, \mathrm{c}: 40^{\circ} \mathrm{C} / \mathrm{m}, \mathrm{d}: 60 \mathrm{mesh}, 40^{\circ} \mathrm{C} / \mathrm{m}$ )

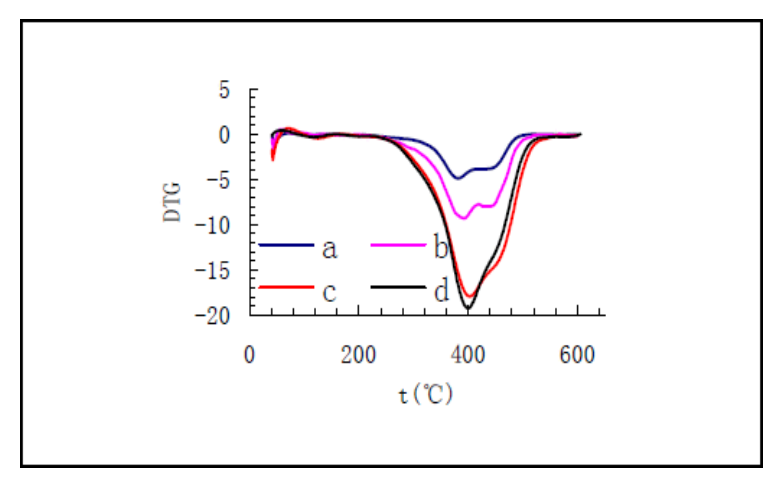

Figure 3. DTG bend for 100 mesh tire dust at unlike heating rate (a: $10^{\circ} \mathrm{C} / \mathrm{m},: 20^{\circ} \mathrm{C} / \mathrm{m}, \mathrm{c}: 40^{\circ} \mathrm{C} / \mathrm{mn}, \mathrm{d}: 60 \mathrm{mesh}, 40^{\circ} \mathrm{C} / \mathrm{m}$ )

These are the main steps of the tire pyrolysis method, which result as the arrival of unstable and dampness at lower temperature and the warm disintegration of common elastic and the decay of polybutadiene and polybutadiene-styrene elastic at higher temperature, individually.

\section{Results}

The publications relating to the pyrolysis of used tyres in terms of the reactors used by their authors, the efficiency of these reactors and the proportion of pyrolytic products obtained: liquid, gas and solid residue, mainly Oil or charcoal.

The present examination the TG aftereffects of 60 work tire powder at a warming rate of $\beta=10 \circ \mathrm{C} / \mathrm{min}$ to demonstrate the weight reduction rate work, $f(\alpha)$. The examination was performed under states of low warming rate and little measure of test, along these lines the impact of warmth exchange and dissemination could be overlooked. The test information in the fundamental scope of $0.1 \leqslant a \leqslant 0.9$ was utilized to figure model. Where as $a<0.1$ or $a>0.9$, the proportion of sign to clamor of the gadget was exceptionally little and the dependability of the test information diminished. While, at early process and conclusion of the pyrolysis, the response has much contrast with the primary response. At the point when pyrolysis temperature is less and higher than $385.3^{\circ} \mathrm{C}$, it was named the low and high temperature organize separately. Moreover the weight reduction of tire pyrolysis was separated into a low temperature organize and a high temperature arrange by the point where the incline of the TG bend changed.

\section{Some Results and discussion from previous experiments conducted by different institutes}

\section{1) The Reaction of $M W$ on tire chips}

The harmful reaction of MW radiation on the tire chips is reported in Figure 4. The pictures describe the progressive decomposition of tires to carbon particles partially coated with polymeric matrix and finally carbon particles only, when all surrounding organic molecules were pyrolyzed[15]. The presence of residual polymer or not fully pyrolyzed matrix was confirmed by FTIR (Fig. 4b). These pictures describe the technical availability to pyrolyze the whole tire without any previous treatments. 


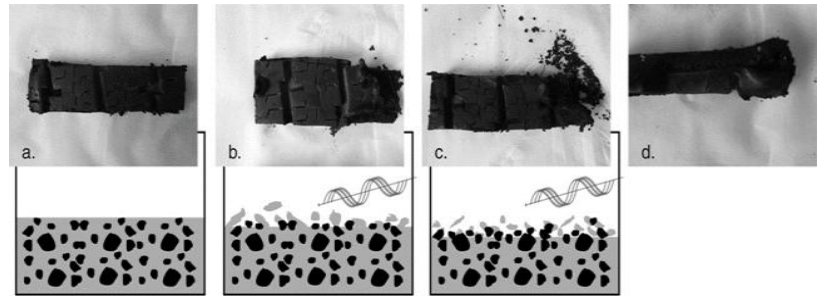

Figure 4. Tire chip when dissimilar MW irradiation period: (a) Tire piece effected (b) Tire piece effected after $60 \mathrm{sec}$ of irritation, (c) Tire piece effected after 90sec of irritation, it flakes if held, (d) Swell influence of a treated tire piece, cross sight

Table II. Pyrolysis products

\begin{tabular}{|c|c|c|c|c|c|c|c|c|c|}
\hline $\begin{array}{l}\mathrm{N} \\
\mathrm{o}: \\
\text { of } \\
\mathrm{E} \\
\mathrm{nt} \\
\text { ri } \\
\text { es }\end{array}$ & $\begin{array}{l}\text { M } \\
W \\
(P)\end{array}$ & $\begin{array}{l}\text { Tire } \\
(\mathrm{M}) \\
(\mathrm{g}) \\
(\mathrm{kW})\end{array}$ & $\begin{array}{l}(\mathrm{kW} / \mathrm{k} \\
\mathrm{g} 2) \mathrm{P} / \\
\mathrm{M} 2\end{array}$ & $\begin{array}{l}\text { TIR( } \\
\mathrm{K})\end{array}$ & $\begin{array}{l}\text { T } \\
\text { EXT } \\
(\mathrm{K})\end{array}$ & $\begin{array}{l}\mathrm{Ti} \\
\mathrm{me} \\
(\mathrm{m})\end{array}$ & $\begin{array}{l}\text { Soli } \\
\text { ds\% }\end{array}$ & $\begin{array}{l}\text { Liq } \\
\text { uid } \\
\%\end{array}$ & $\begin{array}{l}\mathrm{Ga} \\
\mathrm{s} \%\end{array}$ \\
\hline 1 & & $\begin{array}{l}1501 . \\
1\end{array}$ & 1.3 & 533 & 787 & 70 & 50.7 & $\begin{array}{l}39 . \\
3\end{array}$ & 9.0 \\
\hline 2 & 3 & 64.1 & 730.1 & 453 & 617 & 47 & 47.5 & $\begin{array}{l}30 . \\
1\end{array}$ & $\begin{array}{l}22 . \\
3\end{array}$ \\
\hline 3 & 3 & 233.3 & 55.1 & 522 & 764 & 39 & 43.2 & $\begin{array}{l}42 . \\
6\end{array}$ & $\begin{array}{l}14 . \\
2\end{array}$ \\
\hline 4 & 4.7 & 212.8 & 106.0 & 546 & 814 & 15 & 40.6 & $\begin{array}{l}43 . \\
1\end{array}$ & $\begin{array}{l}16 . \\
2\end{array}$ \\
\hline 5 & 6 & 202.8 & 137.6 & 573 & 872 & 14 & 41.6 & $\begin{array}{l}31 . \\
5\end{array}$ & $\begin{array}{l}27 . \\
3\end{array}$ \\
\hline 6 & 3. & 502.8 & 11.9 & 513 & 744 & 59 & 40.6 & $\begin{array}{l}44 . \\
0\end{array}$ & $\begin{array}{l}13 . \\
5\end{array}$ \\
\hline 7 & 1.6 & 252.1 & 23.6 & 523 & 766 & $\begin{array}{l}10 \\
0\end{array}$ & 65.0 & $\begin{array}{l}20 . \\
7\end{array}$ & $\begin{array}{l}14 . \\
2\end{array}$ \\
\hline
\end{tabular}

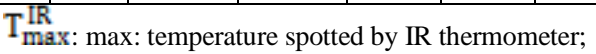

$\mathrm{T}_{\mathrm{max}}^{\mathrm{EXT}}$

EXT: max: temperature concluded.

\section{2) Revenues of products}

The consequences of tests completed at various MW power and mass of tire pieces are accounted for in Table III as shown above

The ratio between microwave power $(\mathrm{P})$ and the tire mass square (M2) was selected as a expressive factor since it gave a good and brief connection between experimental environments and outcomes of pyrolysis test. It is to be noticed that under these experimental circumstances a power connection among the P/M2 ratio and the tire mass (M) can be known $(\mathrm{R} 2=0.9532)$

\section{P $\quad 3.0242 \mathrm{M}-2.045 \mathrm{M} 2$}

In every test MW control was reserved steady over the time. Trials were ceased when gas development was not additionally recognized. Pyrolysis was thought to be finished if natural substance was absent in the buildup.

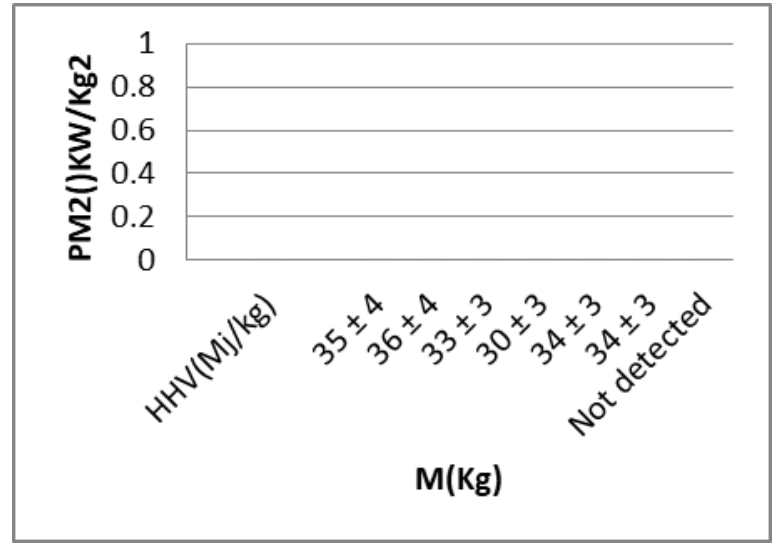

Figure 5. Relationship between P/M2 and M.

\section{3) Solid product}

The solid yields stood unscented black dusts, providing uncompleted pyrolyzed substance was not existing (entry 1-3, 6-7, Table III).

Table III Leading Assets of Solids

\begin{tabular}{|c|c|c|c|c|c|c|}
\hline $\begin{array}{l}\text { ENTR } \\
\mathrm{Y}\end{array}$ & $\begin{array}{l}\mathrm{HHV}( \\
\mathrm{Mj} / \mathrm{kg})\end{array}$ & $\begin{array}{l}\text { LHV( } \\
\mathrm{Mj} / \mathrm{kg})\end{array}$ & & $\begin{array}{l}\text { Definitiv } \\
\text { e } \\
\text { Analysis }\end{array}$ & & \\
\hline & & & $\begin{array}{l}\mathrm{C} \\
(\mathrm{wt} \\
\%)\end{array}$ & $\mathrm{H}(\mathrm{wt} \%)$ & $\begin{array}{l}\mathrm{N}(\mathrm{wt} \% \\
)\end{array}$ & $\mathrm{S}(\mathrm{wt} \%)$ \\
\hline 1 & $36 \pm 4$ & $34 \pm 3$ & $\begin{array}{r}89.3 \\
4\end{array}$ & 0.37 & 0.16 & 2.4 \\
\hline 2 & $36 \pm 5$ & $36 \pm 5$ & $\begin{array}{r}87.9 \\
8\end{array}$ & 0.57 & 0 & 1.8 \\
\hline 3 & $34 \pm 3$ & $33 \pm 3$ & $\begin{array}{r}81.3 \\
2 \\
\end{array}$ & 0.84 & 0.48 & 2 \\
\hline 4 & $30 \pm 4$ & $30 \pm 4$ & $\begin{array}{r}85.7 \\
1\end{array}$ & 3.22 & 0.34 & 1.4 \\
\hline 5 & $33 \pm 3$ & $35 \pm 3$ & $\begin{array}{r}84.9 \\
1 \\
\end{array}$ & 1.62 & 0.41 & 1.5 \\
\hline 6 & $34 \pm 4$ & $33 \pm 3$ & $\begin{array}{r}86.6 \\
4\end{array}$ & 0.31 & 0.79 & 1.6 \\
\hline 7 & $\begin{array}{l}\text { Not } \\
\text { detecte } \\
\text { d }\end{array}$ & $\begin{array}{l}\text { Not } \\
\text { detecte } \\
\text { d }\end{array}$ & $\begin{array}{r}92.0 \\
3\end{array}$ & 0.53 & 0 & $\begin{array}{l}\text { Not } \\
\text { detected }\end{array}$ \\
\hline
\end{tabular}

\section{4) Liquid products}

The investigation demonstrated no noteworthy contrasts among every pyrolysis tests. The fluids don't contain any huge oxygenated hydrocarbons. A portion of the liquid characteristics are accounted for in beneath table (coded "Ln" while " $n$ " is the passage of pyrolysis.

\section{CONCUSLION}

Microwave pyrolysis of tires is appeared as a profitable method to change over an inconvenient waste into a sensible fuel or a wellspring of synthetic substances. To Explore 60,100 and 200 work tire powder under the heating rate of 10 , 20 and $40^{\circ} \mathrm{C} / \mathrm{min}$ the pyrolysis of tire was tried by TG/DTG. The investigation outcomes demonstrated that three phases that made up the tire pyrolysis procedure, containing the 
arrival of unstable and dampness at lesser temperature pursued by the warm deterioration of characteristic elastic and the disintegration of polybutadiene and polybutadiene-styrene elastic at higher temperature, separately. The utilization of a straightforward microwave mechanical assembly for an dynamic heat exchange has been portrayed. Pyrolysis of scrap tires was acknowledged in a brief span. The warming range had a more significant impact on the pyrolysis procedure than tire powder estimate. The procedure gave three distinct items (strong, fluid and gas) that were completely described. The initiation vitality and the recurrence factor were determined. The two system capacities for mass misfortune rate can depict tire pyrolysis well.

\section{ACKNOWLEDGEMENTS}

The authors would like to acknowledge the financial support from National Science Foundation of China (51706044), the Natural Science Foundation of the Jiangsu of China (BK20170666), and the Recruitment Program for Young Professionals in China.

\section{REFERENCES}

[1] Wang, H., et al., Characterization of Bitumen Modified with Pyrolytic Carbon Black from Scrap Tires. Sustainability, 2019. 11(6): p. 1631.

[2] Alvarez, J., et al., Improving bio-oil properties through the fast copyrolysis of lignocellulosic biomass and waste tyres. Waste Management, 2019. 85: p. 385-395.

[3] Zhang, X. and R.C. Brown, Introduction to Thermochemical Processing of Biomass into Fuels, Chemicals, and Power. Thermochemical Processing of Biomass: Conversion into Fuels, Chemicals and Power, 2019: p. 1-16.

[4] Kalogiannis, K.G., S.D. Stefanidis, and A.A. Lappas, Catalyst deactivation, ash accumulation and bio-oil deoxygenation during ex situ catalytic fast pyrolysis of biomass in a cascade thermal-catalytic reactor system. Fuel Processing Technology, 2019. 186: p. 99-109.

[5] Haeldermans, T., et al., Microwave assisted and conventional pyrolysis of MDF-characterization of the produced biochars. Journal of Analytical and Applied Pyrolysis, 2019. 138: p. 218-230.

[6] Martínez, J.D., et al., Waste tyre pyrolysis-A review. Renewable and Sustainable Energy Reviews, 2013. 23: p. 179-213.

[7] van Geldern, R., et al., Stable carbon isotope analysis of dissolved inorganic carbon (DIC) and dissolved organic carbon (DOC) in natural waters-Results from a worldwide proficiency test. Rapid Communications in Mass Spectrometry, 2013. 27(18): p. 2099-2107.

[8] Venderbosch, R.H., Fast pyrolysis. Thermochemical processing of biomass: conversion into fuels, chemicals and power, 2019: p. 175206.

[9] Lin, C.J. and W.L. Hergenrother, Tire compositions comprising epoxidized natural rubber and a functionalized polyolefin. 2005, Google Patents.

[10] Kumarn, S., et al., Investigating the Mechanistic and Structural Role of Lipid Hydrolysis in the Stabilization of Ammonia-Preserved Hevea Rubber Latex. Langmuir, 2018. 34(43): p. 12730-12738.

[11] Schürmann, O., Pneumatic Vehicle Tyres. 2018, Google Patents.

[12] Gauthier-Maradei, P., C.P.T. Ruiz, and M. Capron, Oil and Aromatic Yield Maximization During Pyrolysis of Scrap Tire Rubber. Waste and Biomass Valorization, 2019: p. 1-11.
[13] De Sciarra, F.M and P. Russo, Experimental Characterization, Predictive Mechanical and Thermal Modeling of Nanostructures and Their Polymer Composites. 2018: William Andrew.

[14] Dimpe, K.M., A. Mpupa, and P.N. Nomngongo, Microwave assisted solid phase extraction for separation preconcentration sulfamethoxazole in wastewater using tyre based activated carbon as solid phase material prior to spectrophotometric determination Spectrochimica Acta Part A: Molecular and Biomolecular Spectroscopy, 2018. 188: p. 341-348.

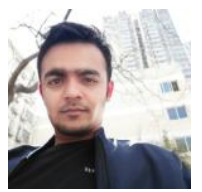

Kaleemullah: The author was born in Pakistan in the year 1992. He holds a bachelors degree in Electrical Engineering from Quaid-e-Awam University of Engineering Science and Technology. He is a Master student at school of Energy and Environment, Southeast University, Nanjing China. His research interests include biomass pyrolysis and gasification and environmental engineering. 